\title{
Effect of BMI on Postoperative Outcome, after Off-Pump CABG, A Prospective Observational Study
}

\author{
Musfeq-Us-Saleheen Khan ${ }^{1}$, Saikat Das Gupta ${ }^{2 *}$, Ambia Afza ${ }^{3}, B_{a p p y ~ B a s a k}{ }^{4}$, MD Kamrul \\ Hasan $^{5}$ and MD Quamrul Islam Talukder \\ ${ }^{1}$ Department of Cardiac Surgery, National Heart Foundation Hospital \& Research Institute, Bangladesh \\ ${ }^{2}$ Department of Cardiac Surgery, Square Hospitals Ltd, Bangladesh \\ ${ }^{3}$ Department of Anesthesia, Delta Medical College \& Hospital, Bangladesh \\ ${ }^{4}$ Department of Cardiothoracic Surgery, Liverpool Heart and Chest Hospital, UK \\ ${ }^{5}$ Department of Cardiac Surgery, National Institute of Cardio Vascular Diseases, Bangladesh
}

\begin{abstract}
Background: Obesity and its complications are global health concerns with rising interests, and in Bangladesh, the scenario is not different. This study was designed to analyze the effect of BMI on postoperative outcomes in patients who underwent Off-Pump Coronary Artery Bypass (OPCAB) graft surgery.
\end{abstract}

Methods: This prospective observational study was conducted from September 2017 to August 2018 in the department of cardiac surgery, NICVD \& 90 patients were divided into two groups. 43 patients in group $\mathrm{A}$, with $\mathrm{BMI} \geq 25 \mathrm{~kg} / \mathrm{m}^{2}$ and 47 patients in group $\mathrm{B}$, with $\mathrm{BMI}<25 \mathrm{~kg} / \mathrm{m}^{2}$.

OPEN ACCESS

${ }^{*}$ Correspondence:

Saikat Das Gupta, Department of Cardiac Surgery, Square Hospitals Ltd, West Panthapath, 5B, Ritz

Lutfunnesa, Road-03, Plot-02, Mirpur-02, Dhaka-1216, Bangladesh, Tel: +8801715739487;

E-mail: saikatdasgupta@ymail.com

Received Date: 27 Jul 2021

Accepted Date: 25 Aug 2021

Published Date: 30 Aug 2021

Citation:

Musfeq-Us-Saleheen Khan, Gupta SD, Afza A, Basak B, MD Kamrul Hasan, MD Quamrul Islam Talukder. Effect of BMI on Postoperative Outcome, after Off-Pump CABG, A Prospective Observational Study. Clin Surg. 2021;

6: 3299.

Copyright $\odot 2021$ Saikat Das

Gupta. This is an open access article distributed under the Creative Commons Attribution License, which permits unrestricted use, distribution,

and reproduction in any medium, provided the original work is properly
Results: In between groups, homogenous distribution was noted in terms of age and sex. Preoperative risk factors, such as hypertension, dyslipidemia, and sternal wound infection, harvest site infection along with post-operative AF, were significantly higher in group A in comparison to group B.

Conclusion: Obese patients undergoing OPCAB surgery should undergo maximum care. Meticulous tissue handling during OPCAB surgery in obese patients is needed to avoid or minimize sternal, and harvest site wound infection.

\section{Keywords: BMI; Off-pump CABG; OPCAB Bangladesh}

\section{Introduction}

Globally, cardiovascular disease is the number one cause of death. An estimated 17.7 million people die from cardiovascular disease every year that represents $31 \%$ of all global deaths, and of these deaths, 7.2 million are due to myocardial infarction. About $80 \%$ of cardiovascular disease deaths take place in low and middle socioeconomic countries and occur almost equally in men and women. If current trends are allowed to continue, by 2030, an estimated 23.6 million people will die from cardiovascular disease. The prime causes contributing to cardiovascular disease include physical inactivity and unhealthy diet [1]. Coronary Artery Disease (CAD) is a group of diseases that includes: stable angina, unstable angina, myocardial infarction, and sudden coronary death. In the early $20^{\text {th }}$ century, coronary heart disease ranked $4^{\text {th }}$ as the cause of death in the USA. At present, it is the number one cause of global death. A study in India found the prevalence of CAD among $2.54 \%$ males and $1.83 \%$ females [1]. Recent data indicates that coronary artery disease prevalence is $1.85 \%$ to $3.4 \%$ in the rural population and $19.6 \%$ in the urban population [2]. According to the WHO data (April 2011), coronary heart disease deaths in Bangladesh reached $17.11 \%$ of total deaths and Bangladesh ranks $25^{\text {th }}$ in the world, in respect of the cause of death due to coronary artery disease [1]. In Bangladesh, as a result of socio-economic transition and urbanization, lifestyle, as well as the dietary pattern, is changing. There is an increasing prevalence of obesity due to the high intake of processed foods and less physical activity. In general, 21.5\% adults have Body-Mass Index (BMI) more than $25 \mathrm{~kg} / \mathrm{m}^{2}$. Increased waist circumference is also alarming, especially in women (33.7\%) [3]. It is well-known that obesity has a major influence on the development of cardiovascular disease, thus leading to worsening physical function and quality of life [4]. Obesity is a global health concern with rising interests. About 0.5 billion world adults are overweight (200 million men and 
300 million women) [1]. Obesity is known as a Body Mass Index (BMI) of 30 or more. Besides, overweight is when a BMI value of 25.0 $\mathrm{kg} / \mathrm{m}^{2}$ to $29.9 \mathrm{~kg} / \mathrm{m}^{2}$. A commonly accepted BMI range for underweight is below $18.5 \mathrm{~kg} / \mathrm{m}^{2}$, and a normal range of BMI is 18.5 $\mathrm{kg} / \mathrm{m}^{2}$ to $25 \mathrm{~kg} / \mathrm{m}^{2}$. As a consequence of obesity, there is an alteration to the vascular endothelium, including the promotion of atherosclerosis, alteration in cardiac function, and promotion of adverse inflammatory change leading to coronary artery disease [5]. Moreover, obesity is highly and increasingly associated with significant postoperative morbidity and mortality in every surgical aspect. Higher BMI has been positively linked to myocardial dysfunction in patients even without coronary artery disease. There is a direct relationship between diastolic dysfunction and systolic impairment in cases of excessive BMI [6]. Obesity is also associated with increased morbidity in the ICU. It markedly increases the risk of pulmonary and airway complications and hampers tracheal intubation. Mechanical ventilation in this population requires specific ventilatory settings due to the mechanical alterations observed in obesity [7]. In a high BMI group of patients, end-expiratory lung volume is decreased, leading to impairment in the mechanics of the respiratory system, lung and chest wall as well as gas exchange. These patients may have apparent healthy lungs; however, the pathophysiological changes induced by obesity make these patients prone to perioperative complications, such as hypoxemia, hypercapnia, and atelectasis. Finally, intraoperative respiratory changes extend to the postoperative period and subsequently necessitate the use of more supplementary oxygen. There is an increase in the need for respiratory physiotherapy or non-invasive ventilation and delay in discharge from the intensive care unit. Besides, obese patients more frequently develop ICU-acquired infections [8]. Obesity also increases the incidence of other risk factors notably diabetes, dyslipidemia, hypertension, and the prothrombotic state [9]. Estimates from the global burden of disease study suggest that by the year 2020 the South Asian part of the world will have more individuals with atherothrombotic cardiovascular disease than any other region [10]. Treatments of coronary heart disease include lifestyle changes, conservative management with medications, interventions, and surgery. When conservative management fails, both angioplasty and Coronary Artery Bypass Grafting (CABG) are used to treat diseased coronary arteries for revascularization accounting for $1.4 \%$ of all operating room procedures performed in 2016. Coronary artery bypass grafting reduces symptoms and improves long-term survival in patients with severe coronary artery disease [11]. The 2004 ACC/AHA CABG guidelines state that $\mathrm{CABG}$ is the preferred treatment for diseases of the Left Main Coronary Artery (LMCA), triple vessel (LAD, LCX, and RCA) coronary artery diseases, a diffuse disease not amenable to be treated with a PCI, and other high-risk patients with severe ventricular dysfunction (i.e. low ejection fraction), or diabetes mellitus. Coronary Artery Bypass Grafting (CABG) is the definitive cardiac surgical procedure of coronary artery revascularization, which improves symptoms and provides long-term survival in coronary heart disease patients [11]. There are two popular options of CABG, one is the Conventional on-pump CABG, and the other is off-pump beating heart $\mathrm{CABG}$ (OPCAB). In conventional CABG, the patient undergoes Cardiopulmonary Bypass (CPB) that has adverse effects, such as neurological assault, renal impairment, respiratory dysfunction, postoperative myocardial infarction, and postoperative bleeding. In $\mathrm{OPCAB}$, the harmful consequence of cardiopulmonary bypass is detached from postoperative outcomes making this procedure much more advantageous than on pump cases [12]. Significant technological advances made in the last decades have allowed OPCAB to be performed with good success rates without the risks related to CPB. As awareness of the potential morbidity of cardiopulmonary bypass increased and as surgical tools and techniques were improved, OPCAB gained widespread acceptance and entered the mainstream of clinical practice. OPCAB is a part of the procedural armamentarium of a growing proportion of surgeons worldwide. Several retrospective studies have reported that OPCAB is associated with lower incidences of renal dysfunction, pulmonary complication, neurologic complications, bleeding, and death [3]. The study shows that in the case of patients undergoing CABG, the risk of sternal wound infection, leg wound infections and atrial arrhythmias were more than twice as high among the overweight and nearly three times higher among the obese $[13,14]$. Overweight patients appear less likely to be selected for surgery than normal-weight patients, and obese patients may have been kept in the hospital longer as a precaution after the postoperative period [11]. Furthermore, in comparison of patients to a normal BMI, patients having high BMI have more visceral adipose tissue, which prolongs the operative time and causes more blood loss during various cardiac and thoracic surgery. During the bypass grafting, anastomosis of the distal grafts becomes difficult in high BMI patients due to the abundant epicardial fat [15]. Another review described that a high BMI group experienced a greater degree of postoperative renal failure, mediastinitis, and prolonged ventilation. All these patients had prolonged ICU days with an increased hospital stay5. Birkmeyer et al. [13] showed although obesity was not associated with increased mortality or postoperative CVA, risks of sternal wound infection were substantially increased in the obese and severely obese. As the number of patients in this particular group is increasing day by day, further research is needed to understand the effects of higher BMI on postoperative outcomes after off-pump coronary artery bypass surgery. National Institute of Cardiovascular Diseases (NICVD), Sher-E-Bangla Nagar, Dhaka, Bangladesh, is performing a crucial role in the field of cardiac surgery countrywide since its birth (1978). At NICVD, off-pump CABG is one of the most common surgical procedures, including patients with normal BMI and high BMI. At NICVD, a study was performed on conventional on-pump CABG; however, no study on the effect of body mass index on postoperative outcomes after OPCAB. Therefore, we completed this study to analyze the effects of body mass index on postoperative outcome after off-pump coronary artery bypass grafting.

\section{Methods}

This prospective observational study was conducted in the department of cardiac surgery, National Institute of Cardiovascular Diseases (NICVD), Sher-E-Bangla Nagar, Dhaka, from $1^{\text {st }}$ September 2017 to $30^{\text {th }}$ August 2018. Patients who underwent Isolated OPCABG in the department of cardiac surgery at NICVD were included in this study and sampling was done by convenient purposive sampling. Combined CABG and valve and other congenital heart surgery, conversion to on-pump CABG, redo CABG, urgent or emergency CABG, pre-operative COPD patient, patient with peripheral vascular disease, patient with renal impairment, patients with preoperative $\mathrm{AF}$, left ventricular ejection fraction $\leq 35 \%$, BMI less than $18.5 \mathrm{~kg} / \mathrm{m}^{2}$ were excluded from the study. A total of 90 patients were prospectively allocated into two groups: Group A included 43 patients with BMI $\geq 25 \mathrm{~kg} / \mathrm{m}^{2}$ whereas 47 patients were in Group B with BMI $<25 \mathrm{~kg} /$ $\mathrm{m}^{2}$. Ethical approval was taken from the Ethical Committee of 
NICVD. The participants and their legal guardians were explained about the study, including the purpose and the importance. Informed written consent was taken from the participants or their guardians by preserving the right to withdraw himself or herself from the study at any time during the study period. Patients' interests were given the highest priority with maintaining full confidentiality. Variables were measured and recorded in all participants by a standard medical scale. BMI was calculated, categorized, and recorded accordingly. All patients underwent off-pump CABG. Post-operatively patients were evaluated in the ICU. Standard ICU protocol used at ICU and shifted to HDU and then to the post-operative ward. Post-Operative Atrial Fibrillation (POAF) was monitored from the day of surgery up to the $4^{\text {th }}$ POD. If there was any incidence of POAF then ECG was done for documentation. The post-operative pulmonary complication was evaluated both clinically and by the radiological method. Neurological assault evaluated clinically by GCS scale. In-hospital outcomes were observed and recorded with one-month follow-up data along it. Total ICU \& post-operative hospital stay, the incidence of sternal and harvest site infection of the patients were also recorded. A structured data sheet was developed containing all the variables of interest. Data were collected by monitoring in ICU \& HDU, at discharge \& one month after discharge.

\section{Data processing and statistical analysis}

Collected data were analyzed statistically by SPSS software version 24.0. Continuous variables were expressed as mean \pm standard deviation and compared using Student's t-test. Categorical variables were expressed as frequencies with percentages and compared using the Chi-square test when and where appropriate. $\mathrm{P}<0.05$ was considered significant. The summarized data were presented in the form of tables.

\section{Results}

Out of 90 patients in our study the mean age was $50.5 \pm 8.0$ years (range 35 to 68 years). The mean age of group A patients were 50.0 \pm 7.6 years (range 37 to 61 years) and group B patients were $50.8 \pm$ 8.3 years (range 35 to 68 years); which was not statistically significant $(\mathrm{p}=0.863)$ (Table 1). Among the study population, the male-female ratio was about 5.4:1. In group A 35 (85.7\%) and group B 41 (92.3\%) were male and the rest $8(18.6 \%)$ and $6(12.7 \%)$ were females in group
A and group B respectively; which was not statistically significant $(\mathrm{p}=0.417)$ (Table 1). The mean BMI of the study population was 24.9 $\pm 3.20 \mathrm{~kg} / \mathrm{m}^{2}$ (range $19.37 \mathrm{~kg} / \mathrm{m}^{2}$ to $32 \mathrm{~kg} / \mathrm{m}^{2}$ ). The mean BMI of group A patients were $28.5 \pm 2.28 \mathrm{~kg} / \mathrm{m}^{2}$ (range $25 \mathrm{~kg} / \mathrm{m}^{2}$ to $32 \mathrm{~kg} / \mathrm{m}^{2}$ ) and group B patients were $22.9 \pm 1.4 \mathrm{~kg} / \mathrm{m}^{2}$ (range $19.37 \mathrm{~kg} / \mathrm{m}^{2}$ to $24.99 \mathrm{~kg} /$ $\left.\mathrm{m}^{2}\right)$, which was statistically significant in between groups $(\mathrm{p}=0.001)$ (Table 1). In group A $24(55.8 \%)$ patients had hypertension, 17 (39.5\%) had diabetes and 26 (60.4\%) had dyslipidemia and in group B 11 (23.4\%) patients had hypertension, $10(21.2 \%)$ had diabetes and 7 (14.9\%) patients had dyslipidemia. There was a statistically significant $(\mathrm{p}=0.001)$ difference between group A and group B patients in terms of hypertension and dyslipidemia. Regarding the extent of coronary artery disease, the single-vessel disease was none in both groups, whereas double vessel disease was 11 (25.5\%) and 9 (19.1\%) in group A and group B respectively and triple vessel disease was 32 (74.4\%) and $38(80.8 \%)$ in group A and group B respectively and it was not significant statistically $(\mathrm{p}=0.594)$ (Table 2$)$. The mean ventilation time (hour) of group A patients was $18.2 \pm 9.3$ hours (range $7 \mathrm{~h}$ to $85 \mathrm{~h}$ ) and in group B patients were $13.2 \pm 4.5 \mathrm{~h}$ (range $5 \mathrm{~h}$ to 96 h) which was not statistically significant $(\mathrm{p}=0.265)$ (Table 3$)$. Postoperative AF in group A and in group B was $12(26 \%)$ and 4 (8.7\%) respectively and it was significant statistically $(\mathrm{p}=0.015)$. The mean ICU stay (days) of group A patients' were $5.5 \pm 2.1$ days, (range 2 to 11 days), and group B patients' were $6.2 \pm 3.7$ days (range 2 to 20 days); which was not statistically significant $(\mathrm{p}>0.05)$. The mean hospital stay (days) of group A, patients were $10.2 \pm 62.5$ days, (range 5 to 15 days) and group B patients were $8.3 \pm 3.7$ days (range 6 to 21 days), and there was no statistically significant $(\mathrm{p}>0.05)$ difference between groups (Table 3 ) in this regard. In group A, patients, other morbidity was found as follows, $6(13.9 \%)$ neurological problem, 1 (2.3\%) reintervention, 18 (41.8\%) sternal wound infection, 15 (34.8\%) harvest site infection, 6 (13.9\%) pulmonary problem. In group B patients, morbidity was found $4(8.5 \%)$ neurological problems, 1 (2.1\%) reintervention, $4(8.5 \%)$ sternal wound infection, $2(4.2 \%)$ harvest site infection, 5 (10.6\%) pulmonary problem, and the differences were not statistically significant $(p>0.05)$ between groups, except sternal wound infection and harvest site infection which were statistically significant $(\mathrm{p}<0.05)$. Out of 90 patients, mortality was found $2(6.5 \%)$ and $3(10.3 \%)$ in group A and group B respectively and the difference was not statistically significant $(p>0.05)$ between group A and group

Table 1: Distribution of Age, Body mass index in study population.
\begin{tabular}{|c|c|c|c|}
\hline & Group A (n=43) & Group B (n=47) & Total $(\mathbf{n}=\mathbf{9 0})$ \\
\hline Age & $50.0 \pm 7.6(37-61)$ & $50.8 \pm 8.3(35-68)$ & $50.5 \pm 8.0(35-68)$ \\
\hline $\begin{array}{c}\text { Sex } \\
\text { No (\%) }\end{array}$ & $35(81.4 \%)$ & $41(87.2 \%)$ & 0.863 \\
\hline BMI & $8(18.6 \%)$ & $6(12.7 \%)$ & Male \\
\hline
\end{tabular}

Figures are Mean \pm SD (range) or Number (Percentage)

Table 2: Distribution of associated preoperative patient characteristics in both groups.

\begin{tabular}{|c|c|c|c|c|c|}
\hline & Group A $(n=43)$ & Group B (n=47) & \multirow{2}{*}{ Chi Value } & \multirow{2}{*}{ Df } & \multirow{2}{*}{$p$ value } \\
\hline & No (\%) & No (\%) & & & \\
\hline Hypertension & $24(55.8)$ & $11(23.4$ & 11.11 & 1 & 0.001 \\
\hline Diabetes & $17(39.5)$ & $10(21.2)$ & 2.77 & 1 & $>0.05$ \\
\hline Dyslipidaemia & $26(60.4)$ & 7 (14.9) & 17.93 & 1 & 0.001 \\
\hline Single vessel & - & -0.0 & & & \multirow{3}{*}{$0.594^{\mathrm{ns}}$} \\
\hline Double vessel & $11(23.8)$ & 9 (19.1) & & & \\
\hline Triple vessel & $32(74.4)$ & $38(80.8)$ & & & \\
\hline
\end{tabular}

Figures are Number (Percentage) 
Table 3: Distribution of Ventilation time, ICU stay and hospital stay of patients.

\begin{tabular}{|c|c|c|c|}
\hline & Group A (n=43) & Group B (n=47) & $\mathbf{p}$ value \\
\hline Ventilation time in hours & $18.2 \pm 9.3$ & $13.2 \pm 4.5$ & 0.265 \\
\hline ICU stay in days & $5.5 \pm 2.1$ & $6.2 \pm 3.7$ & 0.289 \\
\hline Hospital stay in days & $10.2 \pm 2.5$ & $8.3 \pm 3.7$ & 0.489 \\
\hline
\end{tabular}

Figures are Mean \pm SD (range)

Table 4: Distribution of postoperative morbidity and mortality after CABG in both groups.

\begin{tabular}{|c|c|c|c|}
\hline & Group A (n=43) & Group B (n=47) & \multirow{2}{*}{ p value } \\
\cline { 2 - 4 } & No (\%) & No (\%) & \\
\hline Neurological Problem & $6(13.9)$ & $4(8.5)$ & $0.458^{\text {ns }}$ \\
\hline Postoperative AF & $12(27.9)$ & $4(8.5)$ & $0.015^{\mathrm{s}}$ \\
\hline Re exploration & $1(2.3)$ & $1(2.1)$ & $0.651^{\text {ns }}$ \\
\hline Death & $2(4.6)$ & $3(6.3)$ & $0.807^{\text {ns }}$ \\
\hline Sternal wound infection & $18(41.8)$ & $4(8.5)$ & $0.016^{\mathrm{s}}$ \\
\hline Harvest site infection & $15(34.8)$ & $2(4.2)$ & $0.010^{\mathrm{s}}$ \\
\hline Pulmonary problem & $6(14.2)$ & $5(10.6)$ & $0.450^{\text {ns }}$ \\
\hline
\end{tabular}

Figures are Number (Percentage)

$\mathrm{B}$ patients in the chi-square test (Table 4 ).

\section{Study definitions}

BMI (Body Mass Index): BMI = Weight in $\mathrm{kg} /$ (Height in meter $)^{2}$. The BMI is an attempt to quantify the amount of tissue mass (muscle, fat, and bone) in an individual, and then categorize that person as underweight, normal weight, overweight, or obese based on that value 1 .

Cardiopulmonary Bypass (CPB): Cardiopulmonary bypass is a process by which systemic venous blood is taken from the patient, transferred to a pump oxygenator and delivered back to the arterial circulation of the patient.

Conventional CABG: Surgical procedure involving bypass of coronary artery blockages with variety of conduits provided by cardioplegic arrest. Conduits commonly includes Internal mammary artery (both right \& left), Radial artery, Saphenous vein etc.

Off pump coronary artery bypass (OPCAB): Surgical procedure involving bypass of coronary artery blockages with variety of conduits provided without cardioplegic arrest on beating heart. Conduits commonly includes internal mammary artery (both right \& left), Radial artery, Saphenous vein etc.

Prolonged ventilation: prolonged postoperative mechanical ventilation support more than $24 \mathrm{~h}$.

Urgent/emergency CABG: ACC/AHA guidelines provide a class I recommendation for CABG in the context of an ST-Segment Elevation Myocardial Infarction (STEMI) in cases where PCI has been impossible to perform or has failed and the patient has persistent pain and ischemia threatening a significant area of myocardium despite medical therapy. Other class I indications for emergency open heart surgery in the setting of STEMI include the following: Ventricular septal defect related to MI, Papillary muscle rupture, Free wall rupture, Ventricular pseudoaneurysm, Life-threatening ventricular arrhythmias, Cardiogenic shock (ACC/AHA and ESC/EACTS guideline for CABG, 2016).

Postoperative hospital stay: Defined as the duration of postoperative stay of patient in ICU and ward. Normally it is $\leq 7$ days.
However, if there is indication for discharge on or before $7^{\text {th }}$ day, yet the patient prefers to prolong his/her stay for personal convenience then it will not be considered as a prolonged hospital stay.

\section{Discussion}

Obesity is considered to be a high-risk factor in patients undergoing OPCABG surgery. A high BMI $\left(\right.$ BMI $\left.>25 \mathrm{~kg} / \mathrm{m}^{2}\right)$ and especially obesity $\left(B M I>30 \mathrm{~kg} / \mathrm{m}^{2}\right)$ are attended with the presentation of co-morbidity, like cardiovascular disease, diabetes mellitus, dyslipidemia, hypertension, etc. With increasing BMI, the co-morbidity increases. Obesity alters the pulmonary function causing an increase in functional residual capacity and a decrease in vital capacity and maximum voluntary ventilation. In several score systems, obesity is not recognized as a variable needed for risk stratification, and several authors suggest that obesity does not influence mortality although there is an increased risk of in-hospital and early postoperative morbidity after CABG surgery. In our study, the mean age in the non-obese group requiring $\mathrm{CABG}$ is slightly higher than the obese group that is statistically not significant. Similar results were observed in /the several studies [13,14]. A male preponderance was observed in both obese and non-obese groups with an overall male-female ratio of 5.4:1. In other series, obese patients were more likely to be men [10]. Obese patients were more likely to have hypertension and dyslipidemia in our study, compared to non-obese patients. In the non-obese group, only $23.4 \%$ were hypertensive, with dyslipidemia in $14.9 \%$. There was a statistically significant difference between the obese and non-obese groups in terms of hypertension and dyslipidemia. This observation coincides with a similar study [14]. In this series, preoperative patient characteristics like the extent of coronary disease showed no statistically significant difference between the obese and non-obese groups. This study had shown that obesity was not a risk factor for in-hospital mortality. In the obese group, mortality was $4.6 \%$, whereas in the non-obese group it was $6.3 \%$, which is in concurrence with some studies [16,17]. Another similar study found a significant increase in in-hospital mortality in obese patients who had a BMI higher than $35 \mathrm{~kg} / \mathrm{m}^{2}$. They found that moderate obesity (BMI $\left.>35 \mathrm{~kg} / \mathrm{m}^{2}\right)$ was associated with a slight but statistically significant increase in risk-adjusted increase in mortality, and those with extreme obesity $\left(\mathrm{BMI}>40 \mathrm{~kg} / \mathrm{m}^{2}\right)$ had a nearly $50 \%$ increase in risk-adjusted mortality [18]. However, in this study, there was no study population having a BMI of $35 \mathrm{~kg} / \mathrm{m}^{2}$. Therefore, the relationship between moderate obesity and mortality could not be assessed. Here, mild obesity may be protective of the stress response and give energy in the postoperative period as mentioned in a previous study [13]. This study found that obesity only increases the risk of wound infections that is statistically significant. There is an increased risk of AF as another form of morbidity among obese patients undergoing CABG compared to non-obese patients that are significant as well. Besides, the hospital stay is more in obese patients but not significant statistically. In this study, sternal wound infection was present in $41.8 \%$ of patients in the obese group compared to $8.5 \%$ of non-obese patients. It was statistically significant. Regarding conduit harvest site infection, $34.8 \%$ of obese patients developed infections, whereas in the non-obese group infections were found in $4.2 \%$ of patients. The difference in infection between the two groups was statistically significant. The increase in wound infections was also noted in several other studies [17-19]. A previous study found that obesity is an independent preoperative risk factor for sternal wound complications after CABG [20]. Schwann suggests that this higher risk of wound infections may be due to a decreased perfusion of 
adipose tissue and increased incidence of diabetes in obese patients. There is also a relative increase in operating time in obese patients. That suggests an increased open-chest exposure to the environment and may result in an increased incidence of sternal wound infections. Our study has suggested that diabetes mellitus was associated with a postoperative wound infection after coronary artery bypass surgery. This study did not reveal any significant difference for a postoperative neurological problem, re-intervention, or pulmonary problem. In the obese group, morbidity was found in the form of a $13.9 \%$ neurological problem, $2.3 \%$ re-intervention, $14.2 \%$ pulmonary problem, and in the non-obese group neurological problem was $8.5 \%$, re-intervention $2.1 \%$, pulmonary problem $10.6 \%$. All are a little bit higher in the obese group but statistically not significant. This study is in concurrence with other studies. Ventilation time was found more in the obese group with a mean duration of $18.2 \pm 9.3 \mathrm{~h}$ compared to the nonobese group where the mean duration of mechanical ventilation was $13.2 \pm 4.5 \mathrm{~h}$, but it is statistically not significant. It corresponds with other studies. Prolong mechanical ventilation could be due to impaired respiratory function as a result of relatively decreased vital capacity and depression of respiratory drive due to the slow release of anesthetic agents stored in fatty tissue into the blood stream [21,22]. The duration of ICU stays and total hospital stay showed no significant difference between groups. In the obese group, the mean ICU stay was $5.5 \pm 21$ days with a mean hospital stay of $10.2 \pm 2.5$ days. In the non-obese group, the mean duration of ICU and hospital stay was 6.2 \pm 3.7 days and $8.3 \pm 3.7$ days respectively. A little more hospital stay in the obese group may be due to the direct effect of increased wound infections that were not statistically significant. Keeling et al. [23], at a retrospective review of 6,801 patients showed a significant decrease in in-hospital mortality, stroke, new-onset renal failure, and prolonged ventilation for patients with a body mass index $<25$. Despite a higher risk profile, patients with a body mass index $<25$ who underwent off-pump coronary artery bypass grafting experienced a significant reduction in in-hospital mortality [24]. Ilir Hysi, et al. [25] found that severe obesity did not influence postoperative mortality, but the interaction between preoperative renal failure and severe obesity was a crucial mortality prognostic factor. Severe obesity was associated with higher mediastinitis rates, superficial wound infections [24]. Feridoun et al. [12] investigated 1,120 patients who underwent $\mathrm{OPCAB}$, and an important correlation between the underweight/ low BMI group and mortality was observed. Postoperative stroke, postoperative Atrial Fibrillation (AF), and Intra-Aortic Balloon Pump (IABP) use were not associated with BMI. A significant correlation between low BMI, reintubation, ICU stay time, and intubation time was noted. Re-exploration for bleeding was significantly correlated with BMI. They found that low BMI was notably associated with reintubation, prolonged intubation time and ICU stay time. The obese group was also associated with postoperative atelectasis and fever [12]. All patients who survived in this study were followed up. There were no post-discharge mortality and major adverse cardiac events (a new MI, the return of angina pectoris, congestive cardiac failure, rhythm disturbance, and stroke) in both obese and non-obese groups, and hence statistical analysis was not done.

\section{Recommendations}

Proper perioperative soft tissue handling and good post-operative care may reduce morbidity in the obese group. A prospective randomized trial and long-term follow-up are necessary to confirm our findings and to define the long-term clinical and functional results of both groups.

\section{Conclusion}

Nowadays, Coronary revascularization by OPCAB is usually performed in most patients, including patients with increased BMI, and the number of overweight individuals undergoing such procedures will likely increase substantially in the future. We have shown that patients who have a high body mass index appear to have a greater and statistically significant risk of sternal wound infections and harvest site infection regarded as an adverse postoperative outcome. Patients with a high BMI are also at increased risk of postoperative atrial fibrillation. So, obese patients undergoing coronary artery bypass surgery should be treated carefully in the postoperative period.

\section{Study Limitation}

This study had a few limitations. First of all, the surgeries in both groups were not performed by the same surgical team though the same protocol was followed. Secondly, the study population was small. If it was a large-scale study, it would be more representative. Due to a small population, the correlation of diabetes mellitus, hypertension, dyslipidemia, and postoperative infection in the obese and non-obese groups was not possible.

\section{References}

1. World Health Organization. Cardiovascular Diseases (CVDs): Fact sheet. Geneva. WHO. 2018.

2. Monwarul Islam AK, Majumder AAS. Coronary artery disease in Bangladesh: A review. Indian Heart J. 2013;65(4):424-35.

3. Sung SH, Wu TC, Huang CH, Lin SJ, Chen JW. Prognostic impact of body mass index in patients undergoing coronary artery bypass surgery. Heart J. 2011;97(8):648-54

4. Zacharias A, Schwann TA, Riordan CJ, Durham SJ, Shah AS, Habib RH. Obesity and risk of new-onset atrial fibrillation after cardiac surgery. Circulation. 2005;112(21):3247-55.

5. Thourani VH, Keeling WB, Kilgo PD, Puskas JD, Lattouf OM, Chen EP, et al. Guyton. 2011. The impact of body mass index on morbidity and shortand long-term mortality in cardiac valvular surgery. J Thorac Cardiovasc Surg. 2011;142(5):1052-61.

6. Caliskan E, Güsewell S, Oliver MT, Christoph TS, Pavicevic J, Reser $\mathrm{D}$, et al. Does body mass index impact the early outcome of surgical revascularization? A comparison between off-pump and on-pump coronary artery bypass grafting. Interact Cardiovasc Thorac Surg. 2014;19(5):749-55.

7. Tolpin DA, Collard CD, Lee VV, Wei Pan MAE. Obesity is associated with increased morbidity after coronary artery bypass graft surgery in patients with renal insufficiency. J Thorac Cardiovasc Surg. 2009;138(4):873-9.

8. Aldenkortt M, Lysakowski C, Elia N, Brochard L, Tramer MR. Ventilation strategies in obese patients undergoing surgery: A quantitative systematic review and meta-analysis. Br J Anaesth. 2012;109(4):493-502.

9. Wigfield CH, Lindsey JD, Munoz A, Chopra PS, Edwards NM, Love RB. Is extreme obesity a risk factor for cardiac surgery? Eur J Cardiothorac Surg. 2006;29(4):434-40.

10. Reeves BC, Ascione R, Chamberlain MH, Angelini GD. Effect of body mass index on early outcomes in patients undergoing coronary artery bypass surgery. J Am Coll Cardiol. 2003;42(4):668-76.

11. Loop FD, Lytle BW, Cosgrove DM. J. Maxwell Chamberlain memorial paper. Sternal wound complications after isolated coronary artery bypass grafting: Early and late mortality, morbidity, and cost of care. Ann Thorac Surg. 1990;49(2):179-86.

12. Sabzi F, Faraji R. Effect of body mass index on postoperative complications 
in beating coronary artery surgery. Ethiop J Health Sci. 2016;26(6):509-16.

13. Birkmeyer NJ, Charlesworth DC, Hernandez F, Leavitt BJ, Marrin CA, Morton JR, et al. Obesity and risk of adverse outcomes associated with coronary artery bypass surgery. Circulation. 1998;97(17):1689-94.

14. Moutlton MJ, Creswell LL, Mackey ME, Cox JL, Rosenbfoom M. Obesity is not a risk factor for significant adverse outcomes after cardiac surgery. Circulation. 1996;94(9):II87-92.

15. Alam MJ, Ahmed I, Begum R, Jamil K, Moinuddin S. Evaluation of body mass index as a factor of outcome in coronary artery bypass surgery. Cardiovasc J. 2018;10(2):150-7.

16. Brandt M, Harder K, Walluscheck KP, Schottler J, Ratimi A, Moller F. Severe obesity does not adversely affect perioperative mortality and morbidity in coronary artery bypass surgery. Eur J Cardiothorac Surg. 2001;19(5):662-6.

17. Prasad US, Waltker WS, Sang CTM, Campanella C, Cameron EWJ Influence of obesity on the early and long term results of surgery for coronary artery disease. Eur J Cardiothorac Surg. 1991;5(2):67-72.

18. Prabhakar G, Haan CK, Peterson ED, Coombs LP, Cruzzavala JL, Murry GF. The risk of moderate and extreme obesity for coronary artery bypass grafting and outcomes. Ann Thorac Surg. 2002;74(4):1125-30.
19. Engelman DT, Adams DH, Byrne JG, Aranki SF, Collins, Jr JJ, et al. Impact of body mass index and albumin on morbidity and mortality after cardiac surgery. J Thorac Cardiovasc Surg. 1999;118(5):866-73.

20. Schwann TA, Habib RH, Zacharias A. Effects of body size on operative, intermediate, and long-term outcomes after coronary artery bypass operation. Ann Thorac Surg. 2001;71(2):521-30.

21. Kuduvalli M, Grayson AD, Fabri BM, Rashid A. The effect of obesity on midterm survival following coronary artery bypass surgery. Eur J Cardiothorac Surg. 2003;23(3):368-73.

22. Keeling WB, Williams ML, Slaughter MS, Zhao Y, Puskas JD. Off-Pump and on-pump coronary revascularization in patients with low ejection fraction: A report from The Society of Thoracic Surgeons National Database. Ann Thorac Surg. 2013;96(1):83-8.

23. Hysi I, Vincentelli A, Juthier F, Benhamed L, Banfi C, Rousse N, et al. Cardiac surgery and repair of pectus deformities: When and how? Int J Cardiol. 2014;196:83-6.

24. Bojar RM. Manual of perioperative care in adult cardiac surgery, $5^{\text {th }} \mathrm{Ed}$. Chichester: Wiley-Blackwell Publications Ltd. 2011;10-11.

25. Hoque M. ABC of research methodology \& biostatistics. $2^{\text {nd }}$ Ed. 2014;161. 